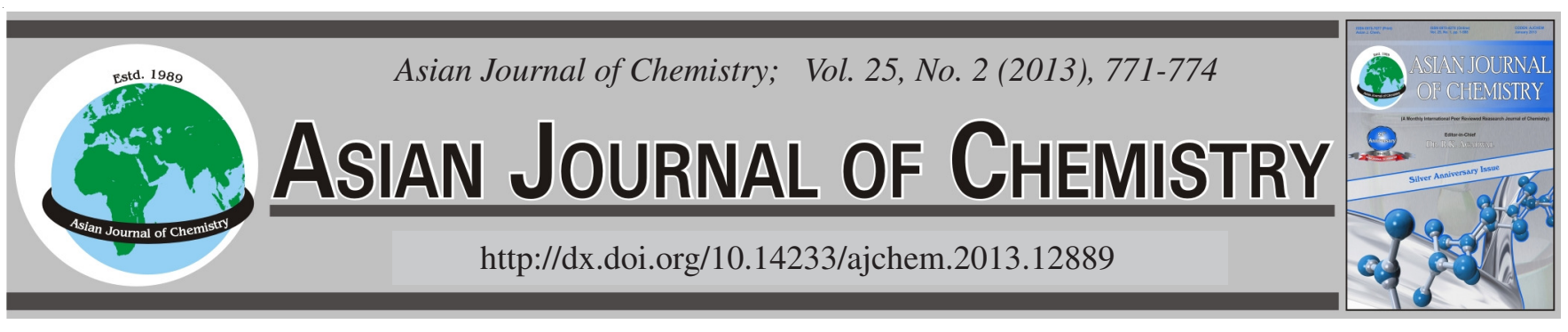

\title{
Studies on Adsorption of Phenol onto Ordered Mesoporous Carbon Prepared by Evaporation-Induced Triconstituent Co-assembly Method
}

Tian-Dong Zhang ${ }^{1}$, Bo Zhou ${ }^{1}$, XiaO-Ying Zeng ${ }^{1}$, Wei Zhe ${ }^{1}$, Li-Li Zhang ${ }^{2}$, Yong-Fang Du ${ }^{3}$, Zhi-Dan Zhang ${ }^{2}$ and Jun Yang ${ }^{2, *}$

${ }^{1}$ Center of Technology, Hongyunhonghe Tobacco (Group) Corporation, Kunming 650202, P.R. China

${ }^{2}$ Department of Chemistry, University of Science and Technology of China, Hefei 230026, P.R. China

${ }^{3}$ Department of Chemical Engineering, Anhui Vocational and Technical College, Hefei 230051, P.R. China

*Corresponding author: Tel/Fax: +86 551 3492065; E-mail: yjun8202@ustc.edu.cn

(Received: 19 October 2011;

Accepted: 20 August 2012)

AJC-11975

Highly ordered mesoporous carbon with complementary pores was prepared by evaporation-induced triconstituent co-assembly method.
The adsorption isotherms were determined from the batch tests during which the effects of initial phenol concentration $(25-1200 \mathrm{mg} / \mathrm{L})$
were investigated. Both Langmuir and Freundlich isotherm models were developed and then compared. The equilibrium data were best
represented by Langmuir isotherm model, showing maximum monolayer adsorption capacity of $480 \mathrm{mg} / \mathrm{g}$ which is two times higher than
that of the activated carbon. The results showed that the prepared ordered mesoporous carbon is the suitable adsorbent for removal of
phenol from aqueous solutions.
Key Words: Ordered mesoporous carbon, Phenol, Equilibrium, Adsorption isotherm.

\section{INTRODUCTION}

Phenol is generally considered to be one of the major and most undesirable pollutants, which is found in the effluents of many industries like petroleum refining, leather, textile manufacturing, olive oil production, coal tar and plastics ${ }^{1,2}$. It can be absorbed by animal body through the respiratory organ, skin and the alimentary canal ${ }^{3}$. It is toxic to organisms at low concentrations and is known to be carcinogenic when present in high amounts ${ }^{4}$. Consequently, many methods and techniques have been suggested to treat phenol from the effluents including adsorption $^{5}$, chemical oxidation ${ }^{6}$, coagulation flocculation ${ }^{7}$ and enzymatic degradation ${ }^{8}$. Among those, adsorption on the activated carbon $(\mathrm{AC})$ is used the most extensively ${ }^{9}$. However, its use is limited in application by its wide pore size distributions, poor mechanical strength, poor adsorption selectivity and inefficient regeneration ${ }^{3}$.

In recent years, the ordered mesoporous carbon (OMC) materials have attracted more and more attention owing to their particular properties such as high surface areas, tunable pore channels and narrow pore size distributions ${ }^{10,11}$. Especially, the complementary mesoporous structure makes the ordered mesoporous carbon materials to be an available substitute of the activated carbon in small-size molecules adsorption such as phenol ${ }^{12}$.
In this study, highly ordered mesoporous carbon with complementary pores have been successfully synthesized by the evaporation-induced triconstituent co-assembly method, wherein soluble resol polymer is used as an organic precursor, prehydrolyzed TEOS is used as an inorganic precursor and triblock copolymer F127 is used as a template. The textural characterization of the prepared ordered mesoporous carbon was carried out by TEM, XRD and $\mathrm{N}_{2}$ adsorption experiment. For the first time, the application as a sorbent was demonstrated by using phenol as model compound at different initial concentrations. The equilibrium was fitted to different models then evaluated to study the adsorption process of phenol on the prepared ordered mesoporous carbon further.

\section{EXPERIMENTAL}

Poly(propylene oxide)-block-poly(ethylene oxide)-blockpoly(propylene oxide) triblock copolymer Pluronic F127 $\left(\mathrm{PEO}_{106} \mathrm{PPO}_{70} \mathrm{PEO}_{106}\right)$ was purchased from Sigma-Aldrich Corp (St.Louis, USA). Tetraethyl orthosilicate (TEOS), phenol, formalin solution $(37 \%), \mathrm{NaOH}, \mathrm{HCl}, \mathrm{HF}$ solution $(40$ $\%$ ) and ethanol were purchased from Sinopharm Chemical Reagent Co. Ltd. (Shanghai, China). The activated carbon (AC) was purchased from Nanjing Linda Active Carbon Co., Ltd. (Nanjing, China). All the above chemicals were used as received without any further purification. And the ordered mesoporous 
carbon was prepared by using triconstituent co-assembly of resol and TEOS as precursors and triblock copolymer F127 as template according to the modified reference ${ }^{13}$. Doubly distilled water was used in all the experiments.

The X-ray diffraction (XRD) measurements were taken on a TTR-III (Rigadu, Japan) using $\mathrm{CuK}_{\alpha}$ radiation (40 KV, $200 \mathrm{~mA}$ ). Transmission electron microscopy (TEM) measurements were taken on a JEOL 2010 microscope (Japan) operated at $200 \mathrm{KV}$; the samples were suspended in ethanol and dropped onto holey carbon film supported on a $\mathrm{Cu}$ grid. Nitrogen adsorption-desorption isotherms were measured at $77 \mathrm{~K}$ with a Micromeritics ASAP 2020 analyzer and the samples were degassed in a vacuum at $200{ }^{\circ} \mathrm{C}$ for $6 \mathrm{~h}$ prior to tests. The Brunauer-Emmett-Teller (BET) method and the BarrettJoyner-Halenda $(\mathrm{BJH})$ model were utilized to calculate the specific surface areas $\left(\mathrm{S}_{\mathrm{BET}}\right)$, the pore volumes and the pore size distributions, respectively. The total pore volumes $\left(\mathrm{V}_{\mathrm{t}}\right)$ were estimated from the adsorbed amount at a relative pressure $\mathrm{P} / \mathrm{P}_{0}$ of 0.994 .

Batch equilibrium studies: The isotherms of phenol adsorption from aqueous solutions were measured by using the static method. The details of adsorption experiment procedure were as follows: $10 \mathrm{mg}$ adsorbent was added into the each $100 \mathrm{~mL}$ flasks containing $10 \mathrm{~mL}$ phenol solution of different initial concentration ranging from $25-1200 \mathrm{mg} / \mathrm{L}$ at $10^{\circ} \mathrm{C}$ for $24 \mathrm{~h}$ to ensure the adsorption process reached equilibrium. The concentrations of phenol before and after adsorption were determined by HPLC (Agilent 1100). The amount of adsorption at equilibrium, $\mathrm{q}_{\mathrm{e}}(\mathrm{mg} / \mathrm{g})$, was calculated by eqn. 1. For comparison, activated carbon was also tested as adsorbent in the same conditions.

$$
\mathrm{q}_{\mathrm{e}}=\frac{\left(\mathrm{C}_{0}-\mathrm{C}_{\mathrm{e}}\right) \mathrm{V}}{\mathrm{W}}
$$

where $\mathrm{C}_{0}$ and $\mathrm{C}_{\mathrm{e}}(\mathrm{mg} / \mathrm{L})$ are the concentrations of phenol initially and at equilibrium, respectively. $\mathrm{V}$ is the volume of the solution (L) and $\mathrm{W}$ is the mass of adsorbent $(\mathrm{g})$.

The equilibrium data were then fitted using two kind of typical isotherm models for single component adsorption, namely the Langmuir and Freundlich models. The model equations are as follows:

$$
\begin{gathered}
\frac{\mathrm{C}_{\mathrm{e}}}{\mathrm{q}_{\mathrm{e}}}=\frac{1}{\mathrm{Q}_{0} \mathrm{~b}}+\left(\frac{1}{\mathrm{Q}_{0}}\right) \mathrm{C}_{\mathrm{e}} \text { Langmuir model } \\
\log \mathrm{q}_{\mathrm{e}}=\log \mathrm{K}_{\mathrm{F}}+\left(\frac{1}{\mathrm{n}}\right) \log \mathrm{C}_{\mathrm{e}} \text { Freundlich model }
\end{gathered}
$$

where $C_{e}$ is the equilibrium concentration of the adsorbate $(\mathrm{mg} / \mathrm{L}), \mathrm{q}_{\mathrm{e}}$ is the amount of adsorbate adsorbed per unit mass of adsorbent (mg/g), $\mathrm{Q}_{0}$ and $\mathrm{b}$ are Langmuir constants related to adsorption capacity and rate of adsorption, respectively. $\mathrm{K}_{\mathrm{F}}$ and $\mathrm{n}$ are Freundlich constants with $\mathrm{n}$ giving an indication of how favorable the adsorption process. The best isotherm model is selected on the basis of correlation coefficient $\left(\mathrm{R}^{2}\right)$.

\section{RESULTS AND DISCUSSION}

Characterization of ordered mesoporous carbon: The small-angle XRD pattern (Fig. 1) for the prepared ordered

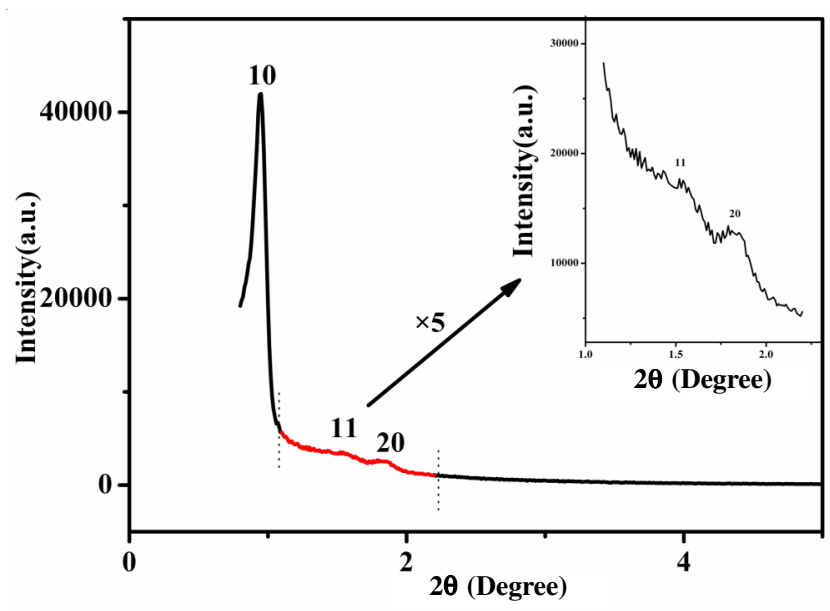

Fig. 1. XRD spectra of the prepared ordered mesoporous carbon

mesoporous carbon exhibits three diffraction peaks at a $2 \theta$ range of $0.5-2.0^{\circ}$ that can be indexed as $(10),(11),(20)$ reflections associated with $2 \mathrm{D}$ hexagonal $\mathrm{p} 6 \mathrm{~mm}$ symmetry ${ }^{11,13}$. This observation indicates that the prepared ordered mesoporous carbon has a high degree of hexagonal mesoscopic organization. The intense (10) peak reflects a d-spacing of $9.3 \mathrm{~nm}$, which corresponds to a large unit-cell parameter $(10.7 \mathrm{~nm})$.

A more detailed texture property is revealed by TEM images, as shown in Fig. 2. The prepared ordered mesoporous carbon shows large domains of highly ordered stripe-like arranged (Fig. 2a) and hexagonally images (Fig. 2b), viewed along the (110), (001) directions. The fast Fourier transform (FFT) diffractograms data (Fig. 2 insets) further confirm an ordered $2 \mathrm{D}$ hexagonal structure ${ }^{11,14}$. Its surfaces are uneven, indicative of many complementary pores that caused by many voids on the walls after etching of silica frameworks. The cell parameter obtained from the TEM images is $c a .11 \mathrm{~nm}$, which is consistent with the value determined from the small-angle XRD data.
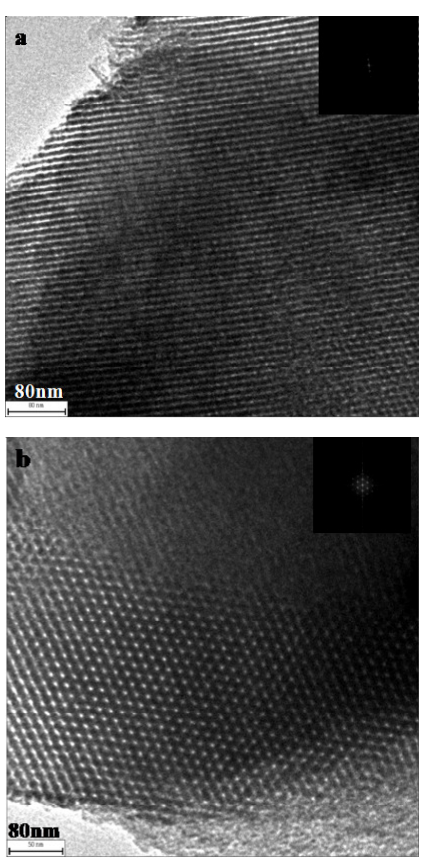

Fig. 2. TEM images of the prepared ordered mesoporous carbon. (a) is the image viewed from 110 direction; (b) is the image viewed from 001 direction 
The $\mathrm{N}_{2}$ sorption isotherm (Fig. 3a) of the prepared ordered mesoporous carbon exhibits a type-IV curve with a sharp capillary condensation step in the $\mathrm{P} / \mathrm{P}_{0}$ range from $0.6-0.7$ and an obvious $\mathrm{H}_{1}$-type hysteresis loop which is typical of mesoporous materials with cylindrical channel ${ }^{13}$. Remarkably, a distinctly adsorption at the relative pressure $\left(\mathrm{P} / \mathrm{P}_{0}\right)$ of 0.1 0.3 is observed, suggesting small pores below $3.5 \mathrm{~nm}$. That caused by etching of silica frameworks, in accordance with TEM observations. Also, the surface area and pore volume are $2281 \mathrm{~m}^{2} / \mathrm{g}$ and $1.92 \mathrm{~cm}^{3} / \mathrm{g}$, respectively. The pore diameter is about $6.5 \mathrm{~nm}$ with a narrow distribution (Fig. 3b).
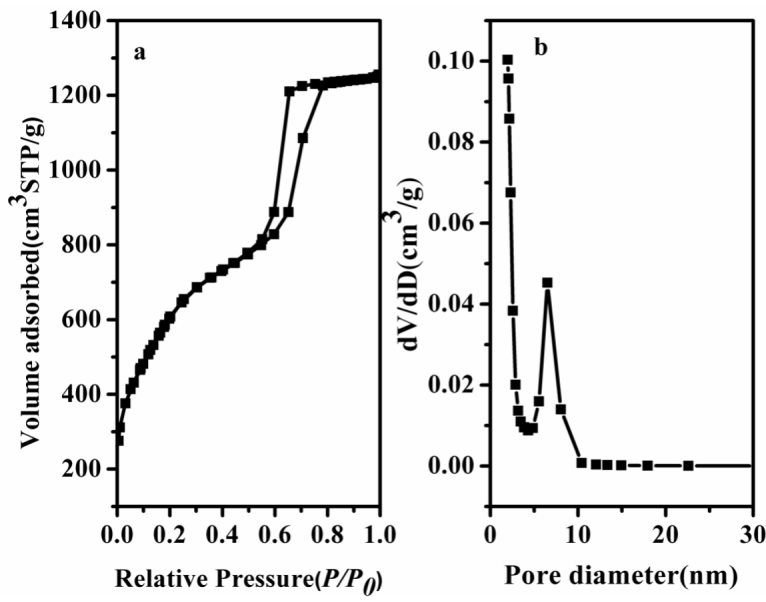

Fig. 3. (a) is the $\mathrm{N}_{2}$ sorption isotherm of the prepared ordered mesoporous carbon at $77 \mathrm{~K}$; (b) is the pore-size distribution curve of the prepared ordered mesoporous carbon

Effect of initial concentration on adsorption equilibrium: The test result (figure not shown) indicated that the adsorption capacities of phenol on the prepared ordered mesoporous carbon and the used activated carbon at equilibrium $\left(\mathrm{q}_{\mathrm{e}}\right)$ increase with the increasing initial concentration. When the initial concentration increased, the mass transfer driving force would become larger, resulting in higher adsorption amount of phenol. It can also be found that the adsorption capacity of the prepared ordered mesoporous carbon is two times higher than that of the activated carbon which was used for comparison in this study. This phenomenon is a credit to the different pore-structures of the prepared ordered mesoporous carbon and the used activated carbon. The prepared ordered mesoporous carbon has the similar primary mesopores with the activated carbon and the abundant complementary mesopores which is absent in the activated carbon ${ }^{12}$. The diameter of complementary mesopores of the prepared ordered mesoporous carbon is below $3.5 \mathrm{~nm}$ which is accessible for phenol molecular with $0.7 \mathrm{~nm}$ diameter. So the phenol adsorption capacity of the prepared ordered mesoporous carbon ( $\mathrm{ca}$. $480 \mathrm{mg} / \mathrm{g}$ ) is higher than that of the activated carbon (ca. 240 $\mathrm{mg} / \mathrm{g})$.

Adsorption isotherms: The adsorption isotherm indicates how the adsorption molecules distribute between the liquid phase and the solid phase when the adsorption process reaches an equilibrium state. The analysis of the isotherm data by fitting them to different isotherm models is an important step to find the suitable model that can be used for design purposes ${ }^{15}$. The

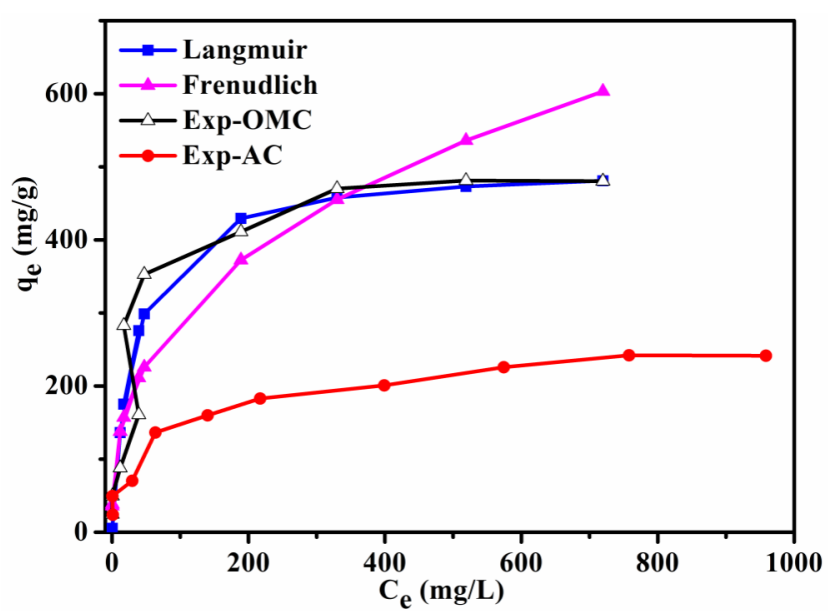

Fig. 4. Equilibrium adsorption isotherm of phenol on the prepared ordered mesoporous carbon and the used activated carbon at $10{ }^{\circ} \mathrm{C}$. And comparing the results of adsorption isotherms of phenol on the prepared ordered mesoporous carbon for experimental Langmuir model and Freundlich model

equilibrium adsorption isotherm of phenol on the prepared ordered mesoporous carbon was shown in Fig. 4. It exhibits a steep increase at low concentrations, indicating high affinity towards the phenol. At high phenol concentrations, the adsorbed amounts increase slightly, showing almost horizontal plateaus.

The Langmuir and Freundlich models were carried out to study the adsorption isotherm. The applicability of the isotherm equation to describe the adsorption process was judged by the correlation coefficients, $\mathrm{R}^{2}$ values.

Fig. 5a presents the fitted curves using Langmuir isotherm model. A straight line with slope of $1 / \mathrm{Q}_{0}$ is obtained when $\mathrm{C}_{\mathrm{e}} /$ $\mathrm{q}_{\mathrm{e}}$ is plotted against $\mathrm{C}_{\mathrm{e}}$. The Langmuir constants $\mathrm{b}, \mathrm{Q}_{0}$ and the correlation coefficients $\mathrm{R}^{2}$ were calculated from eqn. 2 and shown in Table-1.
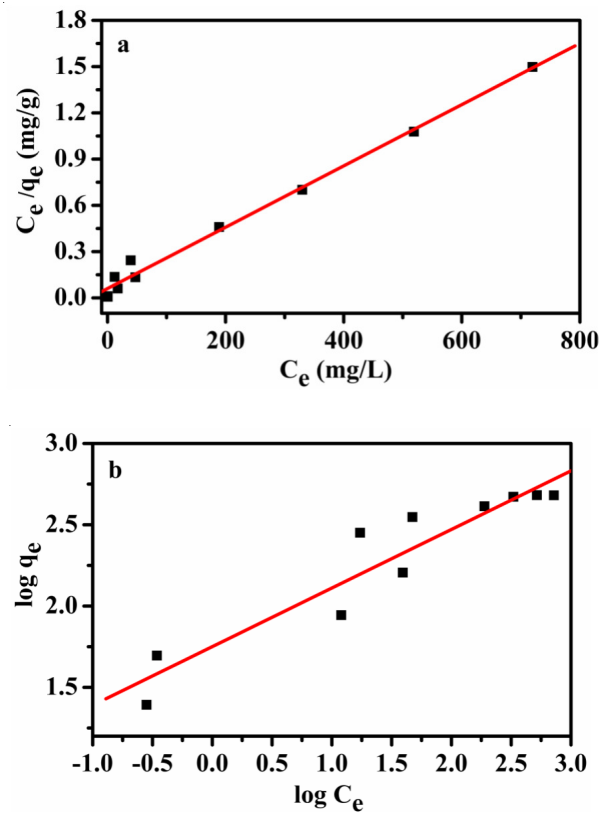

Fig. 5. Adsorption isotherm models of phenol on the prepared ordered mesoporous carbon at $10^{\circ} \mathrm{C}$. (a) is the Langmuir model; (b) is the Freundlich model 
TABLE-1

LANGMUIR AND FREUNDLICH MODEL PARAMETERS FOR ADSORPTION OF PHENOL ON THE ORDERED MESOPORUS CARBON

\begin{tabular}{cccc}
\hline \multicolumn{2}{c}{ Langmuir isotherm } & \multicolumn{2}{c}{ Freundlich isotherm } \\
\hline $\mathrm{B}\left(\mathrm{L} \mathrm{mg}^{-1}\right)$ & 0.0329 & $1 / \mathrm{n}$ & 0.3605 \\
$\mathrm{Q}_{0}\left(\mathrm{mg} \mathrm{g}^{-1}\right)$ & 502.5126 & $\mathrm{~K}_{\mathrm{F}}\left[\mathrm{mg} \mathrm{g}^{-1}\left(\mathrm{~L} \mathrm{mg}^{-1}\right) 1 / \mathrm{n}\right]$ & 56.2924 \\
$\mathrm{R}^{2}$ & 0.9907 & $\mathrm{R}^{2}$ & 0.8931 \\
$\mathrm{R}_{\mathrm{L}}$ & 0.0247 & - & - \\
\hline
\end{tabular}

For Langmuir isotherm, $\mathrm{R}_{\mathrm{L}}$ is used to show the essential character and it can be calculated using the following equation $^{16}$ :

$$
\mathrm{R}_{\mathrm{L}}=\frac{1}{\left(1+\mathrm{bC}_{0}\right)}
$$

where $\mathrm{C}_{0}$ is the highest initial concentration of phenol $(\mathrm{mg} / \mathrm{L})$ and $b(\mathrm{~L} / \mathrm{mg})$ is Langmuir constant. The value of $\mathrm{R}_{\mathrm{L}}$ indicates the type of the isotherm to be either unfavorable $\left(R_{L}>1\right)$, linear $\left(R_{L}=1\right)$, favorable $\left(0<R_{L}<1\right)$ or irreversible $\left(R_{L}=0\right)$. The value of $R_{L}$ in this work was found to be 0.0247 indicating that the sorption of phenol is favorable.

Fig. 5b shows the plot of $\log \mathrm{q}_{\mathrm{e}}$ versus $\log \mathrm{C}_{\mathrm{e}}$ for the Freundlich isotherm. The plot yields a straight line with slope of $1 / n$, which indicated that the adsorption of phenol on the prepared ordered mesoporous carbon was favorable. Accordingly, Freundlich constants $\mathrm{K}_{\mathrm{F}}, \mathrm{n}$ and the correlation coefficients $\mathrm{R}^{2}$ were calculated from eqn. 3 and listed in Table-1.

The experimental isotherm data and the two adsorption isotherm models used in this study are plotted in Fig. 5. It is obvious from Table-1 and Fig. 5 that the Langmuir model yielded the better fit with $\mathrm{R}^{2}$ value higher than 0.99 , as compared to the Freundlich model.

\section{Conclusion}

The ordered mesoporous carbon (ordered mesoporous carbon) with high specific surface areas of $2281 \mathrm{~m}^{2} / \mathrm{g}$ and large pore volumes of $1.92 \mathrm{~cm}^{3} / \mathrm{g}$ was prepared successfully. The tests results show that the prepared ordered mesoporous carbon has the two times higher adsorption capacity $(c a .480 \mathrm{mg} / \mathrm{g}$ at $10{ }^{\circ} \mathrm{C}$ ) than those of the used activated carbon. It indicates that the prepared ordered mesoporous carbon is a promising substitute of the activated carbon for the adsorption of phenol from aqueous solutions over a wide range of concentrations. Equilibrium data were best described by the Langmuir isotherm model. The prepared ordered mesoporous carbon was shown to be a promising substituent adsorbent of the activated carbon for removal of phenol from industrial effluents.

\section{ACKNOWLEDGEMENTS}

The authors acknowledged the financial support of China Tobacco Yunnan Industrial Corporation (No.2009-CP01) and Ministry of Education of Anhui Province of China (No. KJ2010A350) and the Scientific Foundation of State Tobacco Monopoly Administration of China (No. 110200902022).

\section{REFERENCES}

1. P. Girods, A. Dufour, V. Fierro, Y. Rogaume, C. Rogaume, A. Zoulalian and A. Celzard, J. Hazard. Mater., 166, 491 (2009).

2. C.J. Liu, X.Y. Liang, X.J. Liu, Q. Wang, N. Teng, L. Zhan, R. Zhang, W.M. Qiao and L.C. Ling, Appl. Surf. Sci., 254, 2659 (2008).

3. M. Anbia and A. Ghaffari, Appl. Surf. Sci., 255, 9487 (2009).

4. S. Kumar, M. Zafar, J.K. Prajapati, S. Kumar and S. Kannepalli, J. Hazard. Mater., 185, 287 (2011).

5. H. Bouabdesselam, Asian J. Chem., 17, 2284 (2005).

6. X. Hu, F.L.Y. Lam, L.M. Cheung, K.F. Chan, X.S. Zhao and G.Q. Lu, Catal. Today, 68, 129 (2001).

7. T.A. Ozbelge, O.H. Ozbelge and S.Z. Baskaya, Chem. Eng. Process., 41, 719 (2002).

8. A.A. Gungor, Asian J. Chem., 23, 3710 (2011).

9. W. Tanthapanichakoon, P. Ariyadejwanich, P. Japthong, K. Nakagawa, S.R. Mukai and H. Tamon, Water Res., 39, 1347 (2005).

10. B. You, J. Yang, Y.Q. Sun and Q.D. Su, Chem. Commun., 47, 12364 (2011).

11. B. You, J. Yang, G.P. Yong, S.M. Liu and Q.D. Su, Chin. J. Chem. Phys., 24, 365 (2011).

12. X. Zhuang, Y. Wan, C.M. Feng, Y. Shen and D.Y. Zhao, Chem. Mater., 21, 706 (2009).

13. R.L. Liu, Y.F. Shi, Y. Wan, Y. Meng, F.Q. Zhang, D. Gu, Z.X. Chen, B. Tu and D.Y. Zhao, J. Am. Chem. Soc., 128, 11652 (2006).

14. D.Y. Zhao, J.L. Feng, Q.S. Huo, N. Melosh, G.H. Redrickson, B.F. Chmelka and G.D. Stucky, Science, 279, 548 (1998).

15. M. El-Guendi, Adsorp. Sci. Technol., 8, 217 (1991).

16. Q.S. Liu, T. Zheng, P. Wang, J.P. Jiang and N. Li, Chem. Eng. J., 157, 348 (2010). 